\title{
Work and Health
}

John Yaphe, MD MClSc*

W ork is an important determinant of health. Most of us work to live while some of us live to work. Our working hours comprise a significant part of our lives. Our identities are bound up in the work we do. Freud said in 1930 that the bases of society are love and work. "The communal life of human beings had a twofold foundation: the compulsion to work, which was created by external necessity, and the power of love."1:48 In the previous editorial, we explored the relations between sex, gender and health. ${ }^{2}$ The effects of work on health are the focus of this editorial.

We know that our economic health is tied to our physical health. Social status depends partly on the jobs that determine our income. Our work can also be the source of ill health through injuries, toxins and stress. Loss of work can also lead to ill health. ${ }^{3}$ Retirement can adversely affect health. ${ }^{4}$ There is a broad interface between the medical world and the world of work and it can be helpful to family doctors to explore what we know about work and health.

During undergraduate medical education and postgraduate training in family medicine, many educators pay little attention to the importance of work in health and disease. The School of Health Science of the University of Minho is attempting to remedy this by raising awareness of medical students in the second year in a medical sociology course with a seminar on work and health. In the third year, our colleagues from public health discuss issues related to occupational health and industrial diseases in the community health course. During the clinical rotations in family medicine clinics, students observe the mysterious process of the baixa (off-work certification by the family doctor). They also learn of the importance of work as a determinant of social status and income, with direct influences on health.

Work is also tied up with our sense of identity and well-being. The recent economic crisis in Portugal has produced an increase in unemployment, especially among young adults. This has had important effects on

*Associate Professor, Community Health, University of Minho. the mental health of patients seen in primary care. The emigration of young workers with quick minds and strong backs to richer countries in Europe and beyond has also affected those left behind. The search for work and the absence of work are common topics for discussion with the family doctor.

Illness arising in the workplace is well known. Our public health colleagues teach us about the "top six" conditions affecting the health of workers: skin irritants, inhalation of toxins, posture, noise, vibration, and radiation. The recent outbreak of Legionnaire's disease among people exposed to discharge from a factory tower has heightened public awareness of the risks of exposure to industrial wastes. We have a responsibility to promote awareness of these risks, to advise our patients to take the necessary measures to prevent damage (helmets, goggles, masks, gloves, boots and so on), and to screen for early signs of exposure to reduce further damage. While we are agents of the society in the National Health Service, there is no ethical conflict from "double agency". The health and safety of our working patients comes before our concern for the profits of their employers.

Psychological risks in the workplace are less discussed but are well known to family doctors. The problems of burnout in health professionals have been discussed in this journal. ${ }^{5}$ Maslach's burnout inventory has been translated into Portuguese and validated for use among both health care workers and medical students. We need to be aware of the signs and risks of emotional exhaustion, depersonalization, and the sense of loss of personal rewards from our work. This has implications for our patients as well as our own health.

Other psychological risks in the workplace affective health arise from two recently studied phenomena. The first is the effects of shift work. ${ }^{6}$ Changes in shifts are like jet lag. They can throw off the body's internal clock and lead to accidents, irritability, family disruption, and decreased production. Care in managing changes in shifts includes providing adequate time to adjust to a new routine, supervision in the performance of sensitive tasks at the time of a change and minimising frequent 
changes. Melatonin may also have a role to play in helping workers adjust to change in shifts.

A second factor is the role of bullying in the workplace. ${ }^{7}$ While this has been given attention among children in schools, it also occurs in adult populations. Most workplaces have a zero-tolerance policy to bullying but it can be subtle and its effects can be far-reaching. The family doctor can play a role by being aware of patients at risk of bullying. Frequent absence from work for socalled trivial illnesses may raise a warning flag. We may ask the patients questions similar to the ones we use when screening for domestic abuse. Has anyone at work tried to hurt, hit, insult, belittle, or threaten you? Do you feel safe and comfortable at work? We can then refer to the appropriate agencies that ensure safety in the workplace.

When we talk with our patients, we need to be aware of their sense of fulfillment that comes from success in both love and work. When these elements are missing, it can have effects on health. Simple counselling skills are required to explore this issue. They are all within the capabilities of family doctors. We can ask basic questions like: What kind of work do you do? How satisfied are you with your work? How satisfied are you with the rewards you receive from your work? What kind of support do you receive on the job? How does your work affect your health? What risks do you see in your workplace? How can I help you to cope?

Effects of work on health are becoming increasingly important. We encourage our readers to explore these issues with their patients, their students and their colleagues. We also look forward to receiving submissions of original research, reviews, opinions and debate on this important topic.

\section{REFERENCES}

1. Freud S. Civilization and its discontents. New York:W.W. Norton; 1961. ISBN 9780393096231

2. Yaphe J. Sex and gender in family medicine in Portugal [Editorial]. Rev Port Med Geral Fam. 2015;31(1):10-1.

3. Institute for Work and Health. Unemployment and mental health. Toronto: Institute for Work and Health; 2009 [cited 2015 Mar 11]. Available from: http://www.iwh.on.ca/briefings/unemployment-andmental-health

4. Skerret PJ. Is retirement good for health or bad for it? Harvard Health Blog; 2012 [cited 2015 Mar 11]. Available from: http://www.health.harvard.edu/blog/is-retirement-good-for-health-or-bad-for-it201212105625/print/\#comments_controls

5. Yaphe J. On the health of doctors: why we need to look after ourselves first [Editorial]. Rev Port Med Geral Fam. 2013;29(2):86-7.

6. Costa G. Shift work and health: current problems and preventive actions. Saf Health Work. 2010;1(2):112-23. doi:10.5491/SHAW. 2010.1.2.112

7. Carter M, Thompson N, Crampton P, Morrow G, Burford B, Gray C, et al. Workplace bullying in the UK NHS: a questionnaire and interview study on prevalence, impact and barriers to reporting. BMJ Open. 2013;3(6):e002628. doi:10.1136/bmjopen-2013-002628.

\section{CONFLICT OF INTEREST}

None reported

ENDEREÇO PARA CORRESPONDÊNCIA

yonahyaphe@hotmail.com 